\title{
PENGARUH MODEL PEMBELAJARAN KOOPERATIF TIPE COURSE REVIEW HORAY (CRH) TERHADAP HASIL BELAJAR MATEMATIKA SISWA PADA MATERI PERSAMAAN LINEAR SATU VARIABEL DI KELAS VII SMP NEGERI RANTAU SELATAN
}

\author{
Lily Rohanita Hasibuan \\ Program Studi Pendidikan Matematika, STKIP Labuhanbatu,JIn. SM. Raja No. 126A, KM, 3.5 Aek Tapa, Rantauprapat \\ Email: Irohanita30@gmail.com
}

Diterima (April 2018) dan disetujui (Mei 2018)

\begin{abstract}
ABSTRAK
Tujuan penelitian ini yaitu untuk mengetahui pengaruh model pembelajaran kooperatif tipe Course Review Horay $(\mathrm{CRH})$ terhadap hasil belajar matematika siswa pada materi persamaan linear satu variabel di kelas VII SMP Negeri Rantau Selatan. Sampel yang digunakan dalam penelitian ini menggunakan 2 kelas yaitu kelas VII - 6 sebagai kelas eksperimen dan kelas VII - 5 sebagai kelas control yang masing-masing terdiri dari 38 siswa. Metode penelitian yang digunakan adalah quasi eksperimen, teknik pengumpulan data yaitu observasi dan tes sedangkan instrument yang digunakan adalah lembar observasi dan tes hasil belajar dalam bentuk pilihan berganda sebanyak 20 soal dengan 4 pilihan jawaban. Data yang diperoleh dianalisis dengan menggunakan teknik analisis statistic deskriptif dan statistic inferensila yaitu uji - t. Berdasarkan analisis data pada kelas eksperimen diperoleh rata - rata nilai pretes 34,47 dan postes 75,92 dengan rata - rata peningkatan sebesar $63,25 \%$ atau Gain 0,63 kategori sedang dengan standar deviasi 0,1365. Untuk kelas control diperoleh nilai rata -rata pretes 35,13 dan postes 68,68 dengan rata - rata peningkatan hasil belajar kelas kontrol sebesar 50,88 \% atau Gain 0,51 kategori sedang dengan standar deviasi 0,1721. Dari hasil uji beda nilai kedua kelas pada taraf signifikan $\alpha=0,05$ diperoleh thitung $=3,475$ dan tabel $=1,668$ dengan membandingkan antara thitung dan tabel diperoleh thitung $>$ tabel atau 3,475 $>1,668$ maka $\mathrm{Ha}_{a}$ diterima artinya peningkatan hasil belajar matematika siswa yang diajarkan dengan model pembelajaran Course Review Horay $(\mathrm{CRH})$ lebih tinggi daripada model pembelajaran konvensional.
\end{abstract}

Kata Kunci: Model pembelajaran Course Review Horay (CRH) dan Hasil Belajar 


\section{PENDAHULUAN}

Matematika merupakan bagian dari pendidikan. Belajar matematika merupakan salah satu sarana berfikirr ilmiah dan logis serta mempunyai peran penting dalam upaya meningkatkan kualitas sumber daya manusia. Tak heran jika matematika menjadi mata pelajaran wajib bagi siswa SD hingga SLTA dan bahkan juga perguruan tinggi. Ada banyak alasan tentang perlunya belajar matematika. Cornelius (dalam Abdurrahman, 2012:204) mengemukakan 5 alasan perlunya belajar matematika karena matematika merupakan:

(1) Sarana berfikir yang jelas dan logis, (2) sarana untuk memecahkan masalah kehidupan sehari-hari, (3) sarana mengenal pola -pola hubungan dan generalisasi pengalaman, (4) sarana untuk mengembangkan kreativitas, dan (5) sarana untuk meningkatkan kesadaran terhadap perkembangan budaya.

Oleh sebab itu, mengingat pentingnya matematika dalam kehidupan maka guru bidang studi matematika dituntut untuk kreatif menciptakan, merencanakan, pembelajaran matematika dengan sebaik-baiknya.

Berdasarkan hasil observasi yang telaj dilakukan di SMP Negeri Bilah Hulu menunjukkan rendahnya keaktifan siswa pada saat pembelajaran. Hal ini terlihat dari sebagai besar siswa kurang aktif seperti mengajukan pertanyaan, menjawab pertanyaan yang dilontarkan guru ataupun merespon dan menanggapi jawaban dari temannya. Dalam pembelajaran, guru menerapkan model pembelajaran yang berpusat pada guru dimana guru cenderung mentransfer pengetahuan yang dimiliki secara langsung kepada siswa. Kegiatan pembelajaran matematika yang dilaksanakan hanya memposisikan siswa sebagai pendengar ceramah guru, siswa diajarkan teori, diberikan contoh, serta diberikan latihan soal. Siswa tidak didorong untuk aktif dalam mengkonstruksi pengetahuannya sendiri.

Berdasarkan hasil wawancara dengan salah satu guru bidang studi amtematika mengatakan, kegiatan belajar dan mengajar selama ini masih berpusat pada guru, model pembelajaran yang sering digunakan adalah model pembelajaran langsung karena sudah terbiasa serta lebih mudah dalam melaksanakannya dikelas.nilai siswa untuk mata pelajaran matematika tergolong rendah hal ini dilihat dari nilai rata-rata siswa pada semester ganjil yaitu 69,85 sednagkan nilai KKM sekolah tersebut adalah 75 . Minat belajar matematika siswa juga rendah, banyak siswa yang tidak menyukai pelajaran matematika karena merupakan pelajaran yang sulit.

dalam mengajar matematika model pembelajaran yang masih bersifat teacher centered perlu diganti dnegan model pembelajaran yang bersifat student centered. Hal ini bertujuan agar siswa dapat berperan aktif selama proses belajar berlangsung. Pentingnya keaktifan siswa dalam pembelajaran matematika sebagaimana yang dikemukan oleh Wahyudi(2008:5): Pengajaran matematika tidak sekedar berupaya menyampaikan berbagai aturan, defenisi, dan prosedur agar dihapalkan para siswa, tetapi untuk melibatkan pada siswa sebagai partisipan yang aktif dalam proses belajar karena partisipasi aktif para siswa berpotensi untuk memperluas pemahaman konsep matematis mereka.

Oleh karena itu, diperlukan suatu model pembelajaran yang dapat menciptakan suasana belajar yang menyenagkan sehingga dapat menumbuhkan minat dan keaktifan siswa dalam belajar yaitu model pembelajaran kooperatif tipe Course Review Horay (CRH).

Sama halnya dengan model pembelajaran kooperatif pada umumnya, dimana siswa dikelompokkan dalam kelompok kecil yang heterogen dengan kemampuan akademik yang berbeda tujuannya agar mereka saling belajar, bekerja sama menjadi tutor bagi teman sebayanya dan memastikan bahwa seluruh anggota tim telah menguasai pelajaran tesebut. Pada tahap evaluasi seluruh siswa dalam kelompok diberi tes tentang materi itu, pada saat tes ini mereka tidak diperbolehkan saling membantu. Bedanya dengan model pembelajaran kooperatif tipe lain, pada model pembelajaran kooperatif tipe Course Review Horay (CRH) siswa yang menjawab benar harus menyanyikan Yel - yel kelompok mereka. Kemudian, banyaknya yelyel yang diperoleh anggota yang berasal dari kelompok itu diakumulasikan untuk menjadi nilai kelompok dan kelompok yang memiliki skor tertinggi atau jumlah yel-yel yang paling banyak diberi hadiah atau penghargaan oleh guru. Jadi, ciri khas pada model pembelajaran kooperatif tipe Course Review Horay (CRH) ini terletak pada penggunaan yel-yel dalam pembelajaran. Yel-yel yang dinyanyikan dapat menjadi hiburan tersendiri bagi setiap orang yang berada di kelas sehingga suasana belajar menjadi lebih menyenangkan.

Perlunya model pembelajaran yang dapat menciptakan suasana belajar yang 
menyenangkan adalah dapat membuat proses berpikir siswa menjadi lebih optimal sehingga lebih mudah untuk mengembangkan seluruh potensi siswa karena siswa terbebas dari rasa takut dan menegangkan (Sanjaya 2019:34)

Sejalan dengan hal itu, maka dengan menerapkan model pembelajaran kooperatif tipe Course Review Horay $(\mathrm{CRH})$ dalam pembelajaran matematika diharapkan dapat memupuk minat belajar matematika siswa dan mendorong siswa untuk aktif dalam mempelajari matematika, sehingga pada akhirnya dapat berpengaruh baik terhadap hasil belajar matematika siswa..

\section{METODE PENELITIAN}

Penelitian ini termasuk penelitian kuantitatif dengan menggunakan metode quasi eksperimen. Dalam penelitian ini menggunakan perlakuan pembelajaran matematika dengan menggunakan model pembelajaran tipe Course Review Horay ( $\mathrm{CRH}$ ) yang selanjutnya disebut kelas eksperimen. Kelas ini akan memperoleh pretest dan posttest. Penelitian ini dilaksanakan di SMP Negeri 2 Bilah Hulu Kabupaten Labuhanbatu.

Populasi dalam penelitian ini adalah seluruh siswa kelas VII SMP Negeri 2 Bilah Hulu. Sampel dalam penelitian diambil dari populasi terjangkau. Berdasarkan karakteristik yang telah dijelaskan maka pemilihan sampel dilakukan dengan Purposive Sampling (Sampling Pertimbangan) merupakan metode penetapan responden untuk dijadikan sampel berdasarkan pada kriteria-kriteria tertentu. Dengan mengambil satu kelas dari 2 kelas yaitu kelas VII-6 dan VII-5 menggunakan sebanyak 38 siswa.

Instrument yang digunakan dalam penelitian ini berupa tes dan Imbar obseravsi, yaitu tes berbentuk pilihan berganda yang sebanyak 30 butir soal masing-masing memiliki 4 option dalam jawaban untuk mengukur hasil belajar siswa yang diberi perlakuan berupa model pembelajaran Course Review Horay $(\mathrm{CRH})$ maupun yang tidak diberi perlakuan yaitu model pembelajaran konvensional dan observasi digunakan untuk aktivitas siswa pada kelas eksperimen berlangsung yang diberi perlakuan model pembelajaran kooperatif tipe Course Review Horay $(\mathrm{CRH})$ dan menerapkan model pembelajaran secara lamgsung (konvensional). Penelitian ini menggunakan analisis kuantitatif yaitu suatu teknik analisis yang penganalisaannya dilakukan dengan perhitungan, karena berhubungan dengan angka, yaitu dari hasil tes kemampuan hasil belajar matematika yang diberikan.

\section{HASIL PENELITIAN DAN PEMBAHASAN}

\subsection{Deskripsi Data Hasil Kelas Eksperimen}

Untuk mengetahui gambaran deskripsi data pretest hasil belajar matematika siswa sebagaimana berdistribusi pada tabel dibawah ini:

Tabel 4.1 Hasil Pretest Kelas Eksperimen Kemampuan Pemahaman Konsep

\begin{tabular}{|l|c|c|}
\hline \multirow{2}{*}{ No. } & $\begin{array}{c}\text { Pemusatan dan } \\
\text { Penyebaran Data }\end{array}$ & Pretest \\
\hline 1 & Mean & 34.47 \\
\hline 2 & Standart Deviasi & 0.1365 \\
\hline 3 & Varians & 0.51 \\
\hline 4 & Skor Tertinggi & 40.00 \\
\hline 5 & Skor Terendah & 20.00 \\
\hline
\end{tabular}

Review Horay $(\mathrm{CRH})$ dengan jumlah siswa

Berdasarkan hasil tes yang diberikan kepada siswa di kelas eksperimen dengan menggunakan model pembeljaran tipe Course sebanyak 38, maka diperoleh deskripsi data hasil posttest sebagai berikut :

Tabel 4.2 Hasil Post-Tes Kelas Eksperimen Kemampuan Pemahaman Konsep

\begin{tabular}{|c|c|}
\hline Interval dan Penyebaran Data & Jumlah atau Nilai \\
\hline Mean & 75.92 \\
\hline Standar Deviasi & 0.1365 \\
\hline
\end{tabular}




\begin{tabular}{|c|c|}
\hline Varians & 0.51 \\
\hline Skor Tertinggi & 90.00 \\
\hline Skor Terendah & 65.00 \\
\hline
\end{tabular}

Berdasarkan data yang diperoleh dari

Hasil Penelitian Uji Normalitas Tes Hasil Belajar Matematika
Siswa di Kelas Eksperimen nilai pretest dan posttest, maka diperoleh hasil

uji normalitas seperti tabel dibawah ini:

Tabel 4.3 Rekapitulasi Hasil Perhitungan Uji Normalitas di Kelas Eksperimen

\begin{tabular}{|l|l|c|l|l|}
\hline Data & Kelas & $X_{\text {hitung }}$ & $X_{\text {tabel }}$ & Kesimpulan \\
\hline Pretest & VII-6 & 0.1077 & 0.1437 & Ho diterima (normal) \\
\hline Posttest & VII-6 & 0.1008 & 0.1437 & Ho diterima (normal) \\
\hline
\end{tabular}

Berdasarkan tabel 4.3 diatas menunjukkan bahwa data nilai pretest dan posttest hasil belajar matematika dengan menggunakan model pembelajaran Course Review Horay $(\mathrm{CRH})$ di kelas eksperimen berdistribusi normal. Hal ini ditunjukkan dari nilai thitung yaitu 0.1077 dan 0.1437 lebih kecil dari nilai tabel yaitu 0.1077 dengan $\alpha=0,05$ dan $\mathrm{dk}=37$. Artinya $\mathrm{X}^{2}$ hitung $\leq \mathrm{X}^{2}$ tabel, maka $\mathrm{H}_{\mathrm{o}}$ diterima

\begin{abstract}
Uji Homogenitas Tes Hasil Belajar Matematika Siswa di Kelas Eksperimen

Setelah data pretest dan posttest berdistribusi normal, langkah selanjutnya data memiliki varians yang sama atau tidak. Hasil data dapat dilihat seperti tabel dibawah ini:
\end{abstract}

Table 4.4 Rekapitulasi Hasil Perhitungan Uji Homogenitas

\begin{tabular}{|l|l|l|l|l|l|}
\hline Data & Kelas & \multicolumn{1}{|c|}{$\mathrm{N}$} & F $_{\text {hitung }}$ & $F_{\text {tabel }}$ & Kesimpulan \\
\hline $\begin{array}{l}\text { Pretest dan } \\
\text { Possttest }\end{array}$ & VII-6 & 38 & 1.591 & 1.73 & Homogen \\
\hline
\end{tabular}

Uji $t$ Tes Kemampuan Hasil Belajar

Berdasarkan tabel 4.4 diatas diketahui bahwa nilai $F_{\text {hitung }}$ sebesar 1.591 dan $F_{\text {tabel }}$ sebesar 1.73 dengan taraf signifikan 0,05 dan $\mathrm{df}=38$, maka dapat disimpulkan 1,591 $<1,73$ bahwa $\mathrm{H}_{\circ}$ diterima. Artinya bahwa data pre-test dan post-test kelas eksperimen bersifat homogen.

Tabel 4.5 Rekapitulasi Hasil Perhitungan Uji t di Kelas Eksperimen

\begin{tabular}{|c|c|c|c|c|}
\hline Data & $\begin{array}{c}\text { Kela } \\
\mathrm{S}\end{array}$ & $\mathrm{N}$ & thitung & Kesimpulan \\
\hline Pretest dan postest & $\mathrm{VII}-6$ & 38 & -0.295 & $\mathrm{H}_{0}$ ditolak $\mathrm{H}_{\mathrm{a}}$ diterima \\
\hline
\end{tabular}

Berdasarkan tabel 4.5hasil perhitungan uji t yang ditunjukkan pada tabel diatas dengan taraf signifikan $\alpha=0,05 / 2=0,025$ (dua sisi). Kemudian dicari tabel pada tabel distribusi $t$ dengan ketentuan $\mathrm{db}=\mathrm{n}-1, \mathrm{db}=38-1=37$. Sehingga $\left.t_{(0,}, 0295\right)=2,042$, sehingga dalam kasus ini ttabel yang dimaksud adalah 1,68 dan 0,295 . Jadi $2,042 \geq 1,68 \leq-0,295$ yang berarti terdapat pengaruh hasil belajar matematika yang menggunakan model pembelajaran Course Review Horay (CRH) di kelas
Setelah data berdistribusi normal dan homogen, maka dapat dilakukan uji t-test dengan teknik paired samples $t$-test. Hasil yang diperoleh dari perhitungan uji $t$ seperti tabel dibawah ini: eksperimen yang signifikan antara pre-test maupun post-test.

\section{Hasil Observasi Aktivitas Siswa}

Dalam menganalisis aktivitas siswa digunakan skala Likert. Jawaban setiap item instrumen yang menggunakan skala Likert mempunyai gradasi aktif dan cukup aktif. Observasi aktivitas berisi pernyataanpernyataan yang berkaitan dengan aktivitas siswa terhadap pembelajaran matematika menggunakan model pembelajaran tipe Course 
Hal $30-35$

Review Horay $(\mathrm{CRH})$. Hasil rekapitulasi aktivitas siswa dapat dilihat pada tabel berikut :

Tabel 4.6 Rekapitulasi Pertanyaan Positif Aktivitas Siswa

\begin{tabular}{|c|c|c|c|}
\hline Pertemuan & $\begin{array}{c}\text { Jumlah } \\
\text { Skor }\end{array}$ & Nilai & Keterangan \\
\hline I & 716 & 58,88 & Cukup Aktif \\
\hline II & 803 & 65,71 & Aktif \\
\hline III & 864 & 71,05 & Aktif \\
\hline Rata-rata & 151 & 83.88 & Aktif \\
\hline \multicolumn{3}{|c}{ belajar siswa diperoleh }
\end{tabular}

Berdasarkan data diatas dapat disimpulkan bahwa persentase perkembangan aktivitas siswa dalam memperhatikan, mendengarkan penjelasan guru, megajukan pertanyaan, bekerja sama, memberikan jawaban dan menyampaikan ide-ide atau pendapat pada pertemuan pertama sampai pertemuan ketiga terus meningkat

\section{Pembahasan}

Berdasarkan pengujian hipotesis menggunakan uji $t$ dengan teknik paired samples $t$-test untuk kelas eksperimen pada taraf signifikan $\alpha=0,05$ dengan $\mathrm{db}=\mathrm{n}-1$ yaitu $\mathrm{db}=38-1=37$ maka diperoleh nilai tabel sebesar $-1,995$ dan 1,995 (dua sisi), sedangkan nilai thitung diperoleh sebesar -0,295. Hal ini menunjukkan bahwa -ttabel $>$ thitung $<$ ttabel yaitu $-1,995<-0,295<1,995$-maka Ho ditolak dan Ha diterima. Artinya bahwa kedua kelas antara kelas eksperimen dan control mempunyai kemampuan awal yang sama.

Setelah diketahui kemampuan awal siswa maka selanjutnya memberi perlakuan pada kedua kelas eksperimen diajarkan dengan model pembelajaran kooperatif tipe Course Review Horay $(\mathrm{CRH})$ rata -rata hasil belajar siswa pada kelas ini adalah 75,29 dengan peningkatan rata-rata sebesar $63,25 \%$ atau Gain 0,63 kategori sedang. Sedangkan pada kelas control setelah diberi perlakuan rata -rata hasil belajar siswa menjadi 68,88 dengan peningkatan rata-rata sebesar $50,88 \%$ atau Gain 0,51 kategori sedang. Maka $\mathrm{Ha}$ diterima artinya rata -rata peningkatan hasil belajar matematika siswa kelas eksperimen yaitu kelas yang diperlakuan model pembelajaran kooperatif tipe Course Review Horay $(\mathrm{CRH})$ lebih tinggi dari nilai rata -rata peningkatan hasil belajar matematika siswa kelas control yaitu kelas yang diberi perlakuan model pembelajaran konvensional (model pembelajaran langsung).

Pengaruh model pembelajaran kooperatif tipe Course Review Horay $(\mathrm{CRH})$ terhadap aktif menggunakan model pembelajaran kooperatif tipe Course Review Horay (CRH) aktivitas belajar siswa tergolong aktif. Siswa tidak hanya berperan sebagai penerima pelajaran melalui penjelasan guru secara verbal, tetapi siswa berperan aktif berfikir, bekerjasama, berdiskusi untuk menyelesaikan masalah yang ada dan mengembangkan sikap percaya diri siswa dalam proses pembelajaran. Berbeda halnya dengan model pembelajaran konvensional dengan posisi guru sebagai pengatur utama kegiatan siswa. Siswa hanya sebagai penerima informasi dari guru dan guru lebih banyak member penjelasan atau ceramah yang menjadikan siswa pasif, dengan kata lain proses pembelajaran hanya berlangsung satu arah.

Berdasarkan hasil penelitian dan pengujian hipotesis dapat disimpulkan bahwa model Course Review Horay $(\mathrm{CRH})$ member pengaruh yang lebih baik terhadap hasil belajar matematika siswa daripada model pembelajaran konvensional pada materi persamaan linear satu variabel di kelas VII SMP Negeri 2 Bilah Hulu Kabupaten Labuhan Batu.

\section{KESIMPULAN}

1. Peningkatan hasil belajar siswa yang diberi perlakuan model pembelajaran kooperatif tipe Course Review Horay $(\mathrm{CRH})$ dan Konvensional sama - sama member peningkatan terhadap hasil belajar siswa dengan kategori sedang. Dimana peningkatan hasil belajar siswa dari pretest ke posttes yang diberi perlakuan model pembelajaran kooperatif tipe Course Review Horay $(\mathrm{CRH})$ rata - rata peningkatan sebesar 63,25\% atau dengan nilai Gain 0,63 (sedang) dan yang diebri perlakuan model pembelajarankonvensional dengan rata - rata peningkatan $50,88 \%$ atau dengan nilai Gain 0,51 (Sedang). Berdasarkan hasil perhitungan uji t di dapat peningkatan hasil belajar matematika siswa 
yang diajarkan dengan model pembelajaran kooperatif tipe Course Review Horay $(\mathrm{CRH})$ lebih tinggi daripada model pembelajaran konvensional.

2. Berdasarkan hasil penelitian dan uji hipotesis bahwa model pembelajaran kooperatif tipe Course Review Horay (CRH) member pengaruh yang lebih baik terhadap hasil belajar matematika siswa daripada model pembelajaran Konvensional (Model Pembelajaran Langsung) Pada Materi Persamaan Linear Satu Variabel di Kelas VII SMP Negeri 2 Bilah Hulu Kabuapaten Labuhan Batu.

\section{DAFTAR PUSTAKA}

Abdurrahman, Mulyono, (2002). Anak -anak Berkesulitan Belajar: Teori, Diagnosis dan Remediasinya. PT. Rineka Cipta. Jakarta.

Adi, Dwi, (2001). Kamus Praktis Bahasa Indonesia. Fajar Mulya. Surabaya.

Adinamawan, M.Cholik, et. All. (2010). Matematika Untuk SMP Kelas VII. PT. Gelora Aksara Pratama. Jakarta.

Aqib, Zaenal, (2011). Penelitian Tindakan Kelas (PTK) Untuk Guru SD, SLB, TK. Yrama Widya. Bandung.

Arikunto, Suharsimi, (2009). Dasar - dasar Evaluasi Pendidikan. PT. Bumi Aksara. Jakarta.

Aris Susilo, (2011). Peningkatan Keaktifan dan Hasil Belajar Matematika Pada Aljabar Melalui Strategi Pembelajaran Course Review Horay (PTK Pada Siswa Kelas VII A Semester Gasa MTs Negeri Gondangrejo Filial Ngadiluwih Karanganyar Tahun Ajaran 2010/2011). Skripsi Sarjana. Jurusan Pendidikan Matematika, Fakultas Keguruan dan IImu Pendidikan Universitas Muhammadiyah Surakarta.

B. Uno, Hamzah dan Nurdin Mohamad. (2012). Belajar Dengan Pendekatan PAIKEM. Bumi Aksara. Jakarta.

Depdiknas, (2003). Undang - Undang Republik Indonesia Nomor 20 Tahun 2003 Tentang Sistem Pendidikan Nasional. CV. Eko Jaya. Jakarta.

Dimyati dan Mudjiono, (2006). Belajar dan Pembelajaran. Rineka Cipta: Jakarta.

Hamalik, Omar. (2010). Proses Belajar Mengajar. PT. Bumi Aksara: Jakarta.

Isjoni, H. (2009). Pembelajaran Kooperatif:: Meningkatkan Komunikasi Antar Peserta Didik. Pustaka Pelajar: Yogyakarta.
Karso, (2007). Pendidikan Matematika I. Pusat Penerbit Universitas Terbuka. Jakarta.

Nasution, S. (2010). Berbagai Pendekatan dalam Proses belajar \& Mengajar. PT. Bumi Aksara. Jakarta.

Sanjaya, Wina. (2009). Strategi Pembelajaran Berorientasi Standar Proses Pendidikan. Kencana. Jakarta.

Shadily, Hasan dan Jhon M. Echols. Kamus Inggris Indonesia. 2005. PT. Gramedia. Jakarta.

Slameto, (2010). Belajar dan Faktor-faktor yang Mempengaruhinya. Rineka Cipta. Jakarta.

Sudjana, N. (2005). Penilaian Hasil Proses Mengajar. PT. Rosdakarya. Bandung.

Suprijono, Agus (2010). Cooperatif Learning: Teori \& Aplikasi PAIKEM. Pustaka Pelajar. Yogyakarta.

Wahyudi, (2008). Pembelajaran dan Modelmodel Pembelajaran: (Pelengkap Untuk Meningkatkan Kompetensi Pedagogis Para Guru dan Calon Guru Profesional). CV. Ipa Abong. Jakarta. 